\section{Effect of natural tetrafluoromethane}

SIR-Tetrafluoromethane $\left(\mathrm{CF}_{4}\right)$, a potent greenhouse gas ${ }^{1}$ with an atmospheric lifetime of at least 50,000 years (ref. 2), is believed to be of purely anthropogenic origin. Here we present evidence that about half the current atmospheric burden of $\mathrm{CF}_{4}$ has accumulated naturally from weak, probably radiogenic, sources in the lithosphere. We detected significant traces of $\mathrm{CF}_{4}$ in natural gas, and extracted appreciable amounts of $\mathrm{CF}_{4}$ and $\mathrm{SF}_{6}$ from a fluorspar $\left(\mathrm{CaF}_{2}\right)$, containing traces of uranium. Both gases could in future be used as geochemical tracers to yield information on fluid transport in the Earth's crust and on the evolution of natural gas deposits. Additionally, determination of the abundance of $\mathrm{CF}_{4}$ and $\mathrm{SF}_{6}$ in cometary or other planetary atmospheres could help to characterize the prevailing radiochemical conditions.

Earlier stratospheric measurements of vertical concentration gradients of $\mathrm{CF}_{4}$ and $\mathrm{C}_{2} \mathrm{~F}_{6}$ indicated that $\mathrm{CF}_{4}$ could be a natural constituent of the Earth's atmosphere $^{3}$. To test this suggestion, other measurements had to be carried out. The Paul Scherrer Institute (PSI) kindly provided sections of an ice core from Colle Gnifetti $(4,450 \mathrm{~m}$ above sea level) in the Monte Rosa massif at the Swiss/Italian border ${ }^{4}$. For dating of the core sections, we used ${ }^{210} \mathrm{~Pb}$ measurements as well as stratigraphic signals (for example, debris from volcanic eruptions), corrected for the 40 years needed to achieve gas closure (T. Blunier, personal communication). We carried out gas analyses at the MaxPlanck-Institut für Aeronomie (MPAE) based on the existing gas chromatography/mass-spectrometer (GC/MS) system with prior cryogenic pre-concentration 5 . After melting about $1 \mathrm{~kg}$ ice in a pressurized glass cylinder with a stainless steel top, we extracted dissolved gases using two different approaches: 'bubbling out' with synthetic air for core section BC144 (gas closure in 1790 \pm 30 ); and 'salting out' with sodium chloride for two sections of BC123

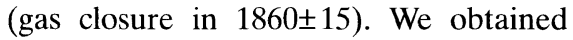
good agreement within the precision $( \pm 20 \%)$ of both methods. We determined the volume of air extracted from closed pores of the core sections using simultaneous GC/MS-measurements of ${ }^{126} \mathrm{Xe}$. We found a mean value of $39 \pm 6$ parts per trillion by volume (p.p.t.v.) of $\mathrm{CF}_{4}$ for the preindustrial atmosphere.

In addition to these ice-core measurements, we analysed air from two sealed glass vessels at MPAE. One (sample AU/Gö) was a 3-litre glass bottle from the $1950 \mathrm{~s}$, the other $(\mathrm{BM} 60)$ a $30-\mathrm{cm}^{3}$ glass sphere from December 1960. We opened both vessels in a water bath to avoid contamination by ambient air, and found that they possessed interior pressures of less than $500 \mathrm{hPa}$, showing that both vessels remained airtight after their production from the hot glass melt. The $\mathrm{CF}_{4}$ mixing ratios did not show a significant deviation from the ice-core measurements.

The figure shows the reconstructed chronology of $\mathrm{CF}_{4}$ based on our stratospheric measurements ${ }^{5}$ and the results of this work. It also includes the two emission models A and B for which historic production numbers of primary aluminium are multiplied with emission factors for $\mathrm{CF}_{4}$ (1.1 and $2.3 \mathrm{~kg} \mathrm{t}^{-1}$, respectively). Scheme A assumes our measured background concentration, whereas scheme B starts with an atmosphere free of $\mathrm{CF}_{4}$. A shows good agreement with all our measurements and requires a realistic emission factor, whereas $B$ reproduces our observations very poorly.

Because it is extremely unlikely that the pre-industrial background of $\mathrm{CF}_{4}$ was

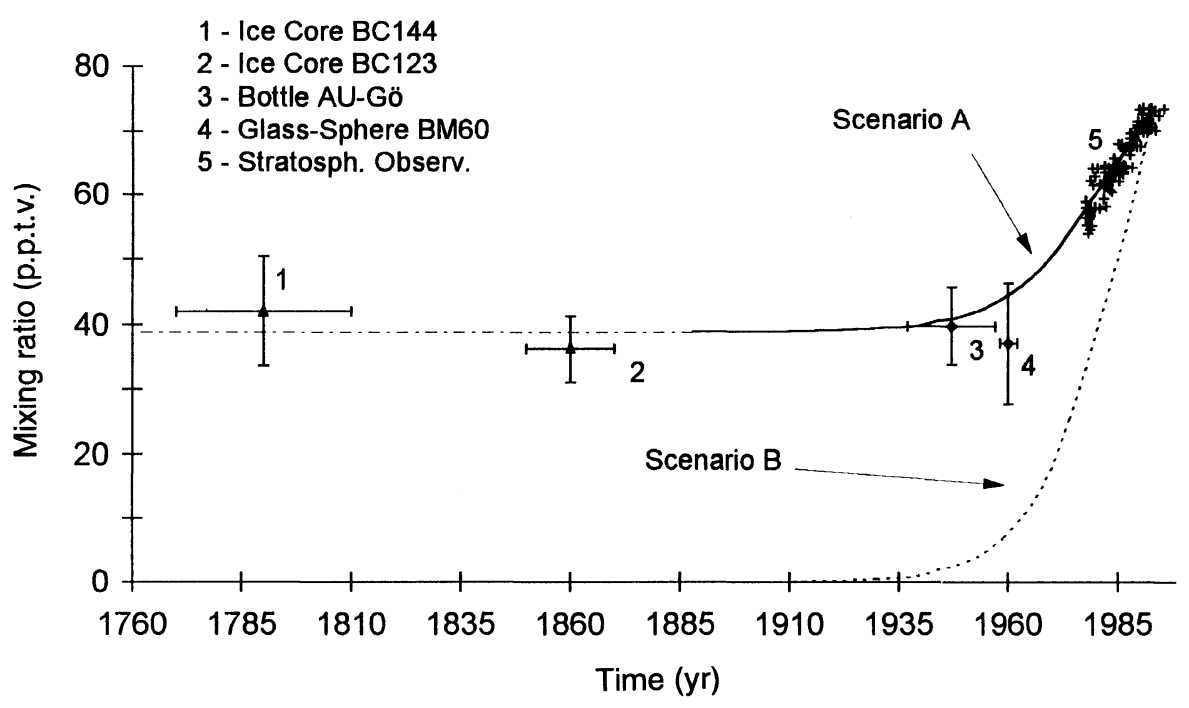

Reconstructed atmospheric chronology of tetrafluoromethane, with two emission models. produced by early activities of humans, we had to identify natural sources of $\mathrm{CF}_{4}$ for a conclusive picture. When trying to measure the efficiency of thermal destruction ${ }^{2}$ of $\mathrm{CF}_{4}$ in flames of natural gas, we found excessive $\mathrm{CF}_{4}$ in the exhausts. The cryogenic pre-concentration technique is not suitable for the measurement of $\mathrm{CF}_{4}$ directly in unburnt natural gas. But because flames of ultra-pure synthetic methane in ambient air did produce excessive $\mathrm{CF}_{4}$, we are confident that surplus $\mathrm{CF}_{4}$ in natural gas flames is not produced through recombination of thermodissociated fluorocarbons, but is indeed present with about 700 p.p.t.v. in the burnt Russian natural gas. If this value is representative for the whole world, no more than $3 \mathrm{t} \mathrm{CF}_{4}$ would be emitted annually by the combustion of natural gas. This source would thus be only a minor contributor to the annual atmospheric input of $15,000 \mathrm{t} \mathrm{CF}_{4}$ through other anthropogenic sources such as aluminium production $^{5}$.

Previous mass spectrometric measurements ${ }^{6}$ provided evidence that $\mathrm{CF}_{4}$ can be produced in fluoride minerals by radiochemical processes. With GC/MS we analysed extracted gases from the same types of fluorspar (Wölsendorf) and could unambiguously identify $\mathrm{CF}_{4}$ as well as $\mathrm{SF}_{6}$ with abundances of several parts per million, whereas $\mathrm{C}_{2} \mathrm{~F}_{6}$ was undetectable. This radiogenic production mechanism of $\mathrm{CF}_{4}$ seems to be responsible for the existence of natural atmospheric $\mathrm{CF}_{4}$ through cold degassing from the Earth's crust, with an annual rate

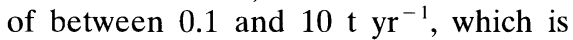
negligible compared with the current anthropogenic emissions.

\section{J. Harnisch}

\section{R. Borchers}

Max-Planck-Institut für Aeronomie (MPAE),

Postfach 20,

37189 Katlenburg-Lindau,

\section{Germany}

\section{P. Fabian}

Universität München,

Lehrstuhl für Bioklimatologie und Immisionsforschung,

Hohenbachernstrasse 22,

85354 Freising-Weihenstephan,

Germany

H. W. Gäggeler*

U. Schotterer

Paul-Scherrer-Institut (PSI),

5232 Villigen-PSI,

Switzerland

*Also at : Institut für Anorganische Chemie, Universität Bern, Freie Strasse 3, 3012 Bern, Switzerland.

1. Roehl, C. M., Boglu, D., Brühl, C. \& Moortgat, G. K Geophys. Res. Lett. 22, 815-818, (1995).

2. Cicerone, R. J. Science 206, 59-61 (1979).

3. Fabian, P., Borchers, R., Krüger, B. C. \& Lal, S. J. Geophys. Res. 92, 9831-9835 (1987).

4. Schotterer, U., Oeschger, H., Wagenbach, D. \& Münnich, K. O. Z. Gletscherk. Glazialgeol. 21, 379-388 (1985).

. Harnisch, J., Borchers, R., Fabian, P. \& Maiss, M. Geophys. Res. Lett. 23, 1099-1102 (1996).

6. Kranz, R. Naturwissenschaften $\mathbf{5 3}, 593-600$ (1966). 